\title{
Degradation of aqueous synthesized CdTe/ZnS quantum dots in mice: differential blood kinetics and biodistribution of cadmium and tellurium
}

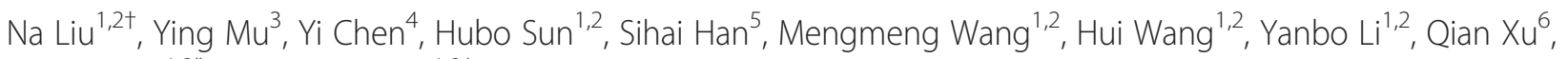
Peili Huang ${ }^{1,2^{*}}$ and Zhiwei Sun ${ }^{1,2+}$

\begin{abstract}
Background: Quantum dots (QDs) have been used as novel fluorescent nanoprobes for various bioapplications. The degradation of QDs, and consequent release of free cadmium ions, have been suggested to be the causes of their overall toxicity. However, in contrast to sufficient investigations regarding the biological fate of QDs, a paucity of studies have reported their chemical fate in vivo. Therefore, the overall aim of our study was to understand the chemical fate of QDs in vivo and explore analytical techniques or methods that could be used to define the chemical fate of QDs in vivo.

Methods: Male ICR mice were administered a single intravenous dose $(0.2 \mu \mathrm{mol} / \mathrm{kg})$ of aqueous synthesized CdTe/ ZnS aqQDs. Inductively coupled plasma-mass spectrometry (ICP-MS) was used to simultaneously measure the concentrations of cadmium ( $\mathrm{Cd}$ ) and tellurium (Te) in the blood and tissues over the course of a 28 day period. We compared the blood kinetic parameters and biodistributions of $\mathrm{Cd}$ and Te, and used the molar ratio of $\mathrm{Cd}: \mathrm{Te}$ as a marker for QDs degradation.

Results: $\mathrm{Cd}$ and Te display different blood kinetics and biodistribution profiles. The Cd:Te ratio in the blood did not vary significantly within the first hour compared with intact CdTe/ZnS aqQDs. The Cd:Te ratio decreased gradually over time from the $6 \mathrm{~h}$ time point on. $\mathrm{Cd}$ accumulated in the liver, kidneys, and spleen. Te was distributed primarily to the kidneys. Sharp time-dependent increases in the Cd:Te ratio were found in liver tissues.

Conclusions: QDs can undergo degradation in vivo. In vitro, QDs are chemically stable and do not elicit the same biological responses or consequences as they do in vivo. Our methods might provide valuable information regarding the degradation of QDs in vivo and may enable the design and development of QDs for biological and biomedical applications.
\end{abstract}

Keywords: Biodistribution, Chemical fate, Degradation, Intravenous, ICP-MS, Kinetics, Mice, Nanoparticles, Quantum dots

\footnotetext{
* Correspondence: huangpl@ccmu.edu.cn

${ }^{\dagger}$ Equal contributors

'Department of Toxicology and Sanitary Chemistry, School of Public Health,

Capital Medical University, No.10 Xitoutiao You An Men, Beijing 100069.

China

${ }^{2}$ Beijing Key Laboratory of Environmental Toxicology, Capital Medical

University, No.10 Xitoutiao You An Men, Beijing 100069, China

Full list of author information is available at the end of the article
} 


\section{Background}

Quantum dots (QDs) are recognized to be novel, highperformance biological probes that are at the forefront of nano-biotechnology research because they possess many attractive optical properties, including a high photoluminescent quantum yield (PLQY), a broad absorption spectrum coupled with narrow emission, and strong photostability [1-3]. However, cadmium (Cd), which is capable of inducing known toxicities in humans (including hepatic, renal, neurologic, and/or genetic toxicities) [4,5], is the most abundant component of QDs. The degradation of QDs, and consequent release of free cadmium ions $\left(\mathrm{Cd}^{2+}\right)$, have been suggested to be the causes of their overall toxicity. Therefore, it is critically important to systematically evaluate the chemical fate of QDs given their widespread applications in biology [6].

Two strategies were used in order to synthesize QDs: organic synthesis (orQDs) and aqueous synthesis (aqQDs). Aqueous synthetic strategies are simpler, cheaper, and more environmentally friendly than organic synthesis methods. More importantly, aqQDs are naturally waterdispersed and do not have large amounts of hydrophilic ligands covering their surfaces. Therefore, aqQDs possess a much smaller hydrodynamic diameter than orQDs. Highly luminescent aqQDs have been thoroughly developed and used in various bioapplications, including bioimaging and protein chips [7-9]. Cadmium-telluride (CdTe) QDs surrounded by a thin shell or cap of zinc sulfides $(\mathrm{ZnS})$ (CdTe/ZnS aqQDs) are one of the most successful examples. As with all QDs, the CdTe core of the CdTe/ZnS aqQDs is composed of covalently bound $\mathrm{Cd}$ and tellurium $(\mathrm{Te})$ that are held at a constant molar ratio $(\mathrm{Cd}: \mathrm{Te})$. As a result of the stability of the covalently bound CdTe core and the apparent 'inertness' of the CdTe complex (as opposed to the reactive nature of $\mathrm{Cd}^{2+}$ ), this bound $\mathrm{Cd}$ complex has no valence charge and, therefore, no biological reactivity. The exposed $\mathrm{CdTe} / \mathrm{ZnS}$ aqQDs are therefore believed by many to be biologically safe and non-toxic. However, if the CdTe core is degraded, the release of $\mathrm{Cd}^{2+}$ and telluride ions $\left(\mathrm{Te}^{2-}\right)$ from the CdTe core will increase the risk of target organ toxicities $[4,5,10]$.

To better understand and predict the efficacy and side effects of QDs in vivo, four key questions need to be addressed: What is the pharmacokinetic profile of QDs? Where are these nanocrystals deposited (tissue disposition of QDs) within the body? How long do the deposited QDs remain in the tissues or organs? What happens to the QDs particles when they are in a biological system? Work conducted by Fischer's group resulted in the first quantitative report on the in vivo biodistribution of QDs in 2006 [11]. Several subsequent in vivo pharmacokinetic studies of QDs have been completed [12-14]. The results of these studies suggest several key points: (i) administered QDs have a rather wide range (from $48 \mathrm{~min}$ to $20 \mathrm{~h}$ ) of half-lives $\left(t_{1 / 2}\right)$ in the bloodstream; (ii) QDs do not remain in the circulation and tend to accumulate in organs and tissues; (iii) QDs that are injected intravenously are more likely to accumulate in the liver, spleen, and kidneys; and (iv) the in vivo behavior of QDs is greatly dependent on their hydrodynamic diameters. QDs with smaller hydrodynamic diameters are more rapidly and efficiently eliminated via renal clearance in mice than those with large hydrodynamic diameters $(>15 \mathrm{~nm})$. In contrast to the sufficient investigations outlined above, there have been relatively few studies addressing the chemical fate of QDs in vivo.

In our previous studies regarding the pharmacokinetics and tissue distribution of CdTe aqQDs, we found that $\mathrm{Cd}$ and $\mathrm{Te}$ display different plasma kinetics and distribution patterns [15]. The different plasma kinetics and distribution patterns of $\mathrm{Cd}$ and $\mathrm{Te}$ imply that $\mathrm{CdTe}$ aqQDs may undergo degradation in vivo. To further explore the degradation of QDs, we investigated the in vivo properties of $\mathrm{CdTe} / \mathrm{ZnS}$ aqQDs, including blood pharmacokinetics and the long-term biodistribution of $\mathrm{Cd}$ and Te. Moreover, based on the atomic weights of $\mathrm{Cd}$ and $\mathrm{Te}$, the $\mathrm{Cd}$ :Te ratios in the blood and tissues over time were calculated and were used to reflect the general stability and conditions of CdTe/ZnS aqQDs in biological systems. As compared with the initial and normal Cd:Te ratio in $\mathrm{CdTe} / \mathrm{ZnS}$ aqQDs, steady or unchanged $\mathrm{Cd}: \mathrm{Te}$ ratios in the blood and tissues over time indicate that the $\mathrm{CdTe} / \mathrm{ZnS}$ aqQD complexes have remained intact. In contrast, alterations in the Cd:Te ratio signify disintegration of the complex. In addition, the chemical fate of $\mathrm{CdTe} / \mathrm{ZnS}$ aqQDs in vitro and in vivo were examined as well. Based on the blood kinetic parameters and biodistributions of $\mathrm{Cd}$ and $\mathrm{Te}$, as well as alterations in the $\mathrm{Cd}$ :Te ratio, we believe that we can assess the chemical fate of $\mathrm{CdTe} / \mathrm{ZnS}$ aqQDs in biological systems. Although QDs have different core compositions (for example, gallium-, copper-, lead-, and arsenidebased QDs), different QDs may behave similarly in biological systems. The information generated from our studies may contribute to the general understanding of QDs and the evaluation of the biological risks associated with their use.

\section{Results}

\section{Characteristics of CdTe/ZnS aqQDs}

For atomic force microscopy (AFM) measurements, only the Z-dimension was used to determine the size in order to avoid probe-related artifacts. These measurements yielded a mean size of $19.3 \pm 2.2 \mathrm{~nm}$. The shape of the $\mathrm{CdTe} / \mathrm{ZnS}$ aqQDs was approximately spherical (Figure 1A). The emission spectra of the aqQDs are presented in Figure 1B. The maximal emission was $652 \mathrm{~nm}$ (at $\lambda \mathrm{ex}=$ $350 \mathrm{~nm}$ ). The concentration of the CdTe/ZnS aqQDs stock 

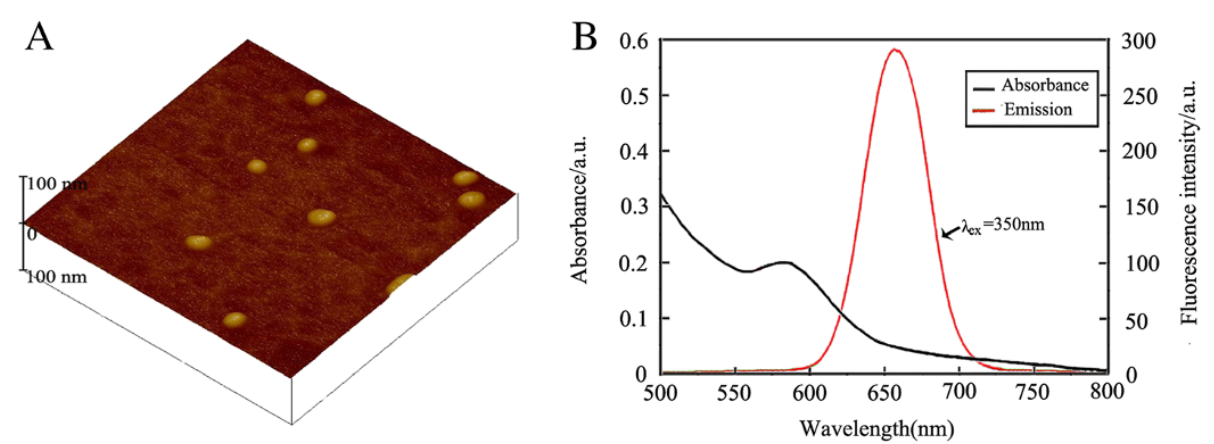

Figure 1 Characteristics of CdTe/ZnS aqQDs: (A) AFM image, (B) absorption and emission spectra. The average size was $19.3 \pm 2.2 \mathrm{~nm}$ in diameter. The maximal emission was observed at approximately $652 \mathrm{~nm}$ following excitation at $350 \mathrm{~nm}$.

solution was $2.5 \mu \mathrm{mol} / \mathrm{ml}$ (calculated based on the molar mass of $\mathrm{Cd}$ ). The $\mathrm{Cd}$ :Te ratio was 3:1, and the molar ratio of zinc $(\mathrm{Zn})$ to $\mathrm{Cd}(\mathrm{Zn}: \mathrm{Cd})$ was $1: 1$.

\section{Stability of CdTe/ZnS aqQDs in vitro}

The stability data for the CdTe/ZnS aqQDs in vitro are shown in Figure 2 and Table 1. Figure 2 illustrates that in the first 20 days, the PLQYs of CdTe/ZnS aqQDs in situ were not significantly different (ranging from 70.3 to $72.3 \%)$. The PLQYs gradually decreased over the next 20 days, and the values had dropped to $43.8 \%$ of their original values 80 days later. Table 1 shows that the maximal emission $(652 \mathrm{~nm})$ of $\mathrm{CdTe} / \mathrm{ZnS}$ aqQDs was not altered by dialyses lasting up to $3 \mathrm{~d}$ in $\mathrm{pH} 7.4$ buffered solutions, but dialysis rapidly reduced the relative fluorescence intensity after $6 \mathrm{~h}$ (from 271.0 to 144.1). After $3 \mathrm{~d}$, only 55.2 remained. In the filtrate, the

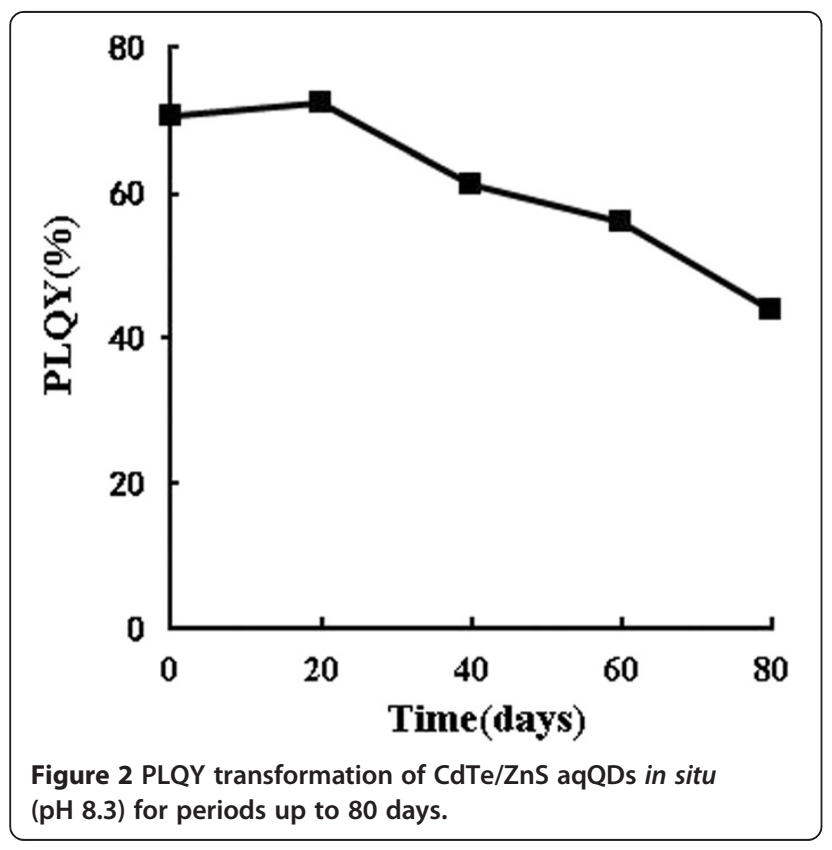

concentrations of $\mathrm{Cd}, \mathrm{Te}$, and $\mathrm{Zn}$ gradually increased with time, but $\mathrm{Cd}$ :Te ratios did not vary significantly (the molar ratio of $\mathrm{Cd}$ and $\mathrm{Te}$ in $\mathrm{CdTe} / \mathrm{ZnS}$ aqQDs used in this study was 3:1). Zn:Cd ratios were not significantly different (the molar ratio of $\mathrm{Zn}$ and $\mathrm{Cd}$ in $\mathrm{CdTe} / \mathrm{ZnS}$ aqQDs used in this study was 1:1) in the first $6 \mathrm{~h}$, but at the $24 \mathrm{~h}, 2$ and $3 \mathrm{~d}$ time-points, the ratios had become slightly elevated (from 1.13:1 to 1.26:1).

\section{Comparative $\mathrm{Cd}$ and Te blood kinetics}

We did not observe significant changes in body or organ weights in the mice after tail vein injections of $\mathrm{CdTe} /$ $\mathrm{ZnS}$ aqQDs (Additional file 1: Table S1). Additionally, no symptoms of illness were observed in the mice at the dose of aqQDs administered during the experimental period, and all of the animals survived until the end of the experimental period.

The $\mathrm{Cd}$ and $\mathrm{Te}$ concentrations in the blood are presented in Table 2. Table 2 shows that blood Cd concentrations were much higher than Te concentrations for the first day after injection. At $3 \mathrm{~d}$ post-injection, the $\mathrm{Cd}$ concentrations were below the limit of detection and were much lower than the Te concentrations. The $\mathrm{Cd}$ : Te ratios did not vary significantly in the first hour. The ratios were 3.01:1 (1 $\mathrm{min}), 2.95: 1$ (15 $\mathrm{min}), 2.95: 1$ (30 $\mathrm{min})$ and 2.94:1 (1 h). All of the ratios were approximately 3:1, which corresponds to the Cd:Te ratio in the $\mathrm{CdTe} / \mathrm{ZnS}$ aqQDs used in this study. From the $6 \mathrm{~h}$ time point on, the Cd:Te ratios decreased gradually over time from 2.48:1 to 1.87:1. The main kinetic parameters shown in Table 3 were fit using a two-compartment model with a weighting factor of $1 / \mathrm{c}^{2}$, in which $\mathrm{Cd}$ and Te varied. $\mathrm{Cd}$ exhibited a significantly greater area under the blood concentration-time profiles (AUC) $(2.16 \pm 0.07 \mu \mathrm{g} \cdot \mathrm{h} / \mathrm{ml}$ vs. $0.99 \pm 0.13 \mu \mathrm{g} \cdot \mathrm{h} / \mathrm{ml}, p<0.01)$, clearance (CL) $(10.40 \pm$ $0.48 \mathrm{ml} / \mathrm{h} / \mathrm{kg}$ vs. $8.99 \pm 1.53 \mathrm{ml} / \mathrm{h} / \mathrm{kg}, p<0.05)$ and a rapider elimination half-life $\left(t_{1 / 2 \beta}\right) \quad(12.41 \pm 0.26 \mathrm{~h}$ vs. $14.40 \pm 1.33 \mathrm{~h}, p<0.05)$ than Te. 
Table 1 Stability of CdTe/ZnS aqQDs in buffer solutions mimicking blood (pH 7.4)

\begin{tabular}{|c|c|c|c|c|c|c|c|}
\hline \multirow[t]{2}{*}{ Time } & \multirow{2}{*}{$\begin{array}{c}\text { Maximal } \\
\text { emission }(\mathrm{nm})\end{array}$} & \multirow{2}{*}{$\begin{array}{c}\text { Relative } \\
\text { fluorescent unit }\end{array}$} & \multicolumn{3}{|c|}{ Metal concentrations in filtrate $(\mathrm{ng} / \mathrm{ml})$} & \multicolumn{2}{|c|}{ Molar ratios of metals in filtrate } \\
\hline & & & Cd & $\mathrm{Te}$ & Zn & Cd:Te & $\mathrm{Zn}: \mathrm{Cd}$ \\
\hline Initial time & 652 & $271.0 \pm 6.5$ & ND & ND & ND & ND & ND \\
\hline $15 \mathrm{~min}$ & 652 & $270.5 \pm 5.8$ & $2.08 \pm 0.12$ & $0.81 \pm 0.01$ & $1.30 \pm 0.01$ & $2.92: 1$ & $1.08: 1$ \\
\hline $30 \mathrm{~min}$ & 652 & $270.6 \pm 7.9$ & $7.20 \pm 0.21$ & $2.90 \pm 0.02$ & $4.08 \pm 0.05$ & $2.82: 1$ & $0.98: 1$ \\
\hline $1 \mathrm{~h}$ & 652 & $270.0 \pm 9.0$ & $7.72 \pm 0.48$ & $2.88 \pm 0.30$ & $4.82 \pm 0.12$ & $3.05: 1$ & $1.08: 1$ \\
\hline $6 \mathrm{~h}$ & 652 & $144.1 \pm 12.8$ & $8.52 \pm 0.95$ & $3.36 \pm 0.45$ & $5.02 \pm 0.38$ & $2.88: 1$ & $1.02: 1$ \\
\hline $24 \mathrm{~h}$ & 652 & $104.2 \pm 11.1$ & $11.90 \pm 1.06$ & $4.91 \pm 0.36$ & $7.77 \pm 1.01$ & $2.75: 1$ & $1.13: 1$ \\
\hline $2 d$ & 652 & $86.2 \pm 10.9$ & $12.87 \pm 1.24$ & $5.04 \pm 0.44$ & $9.08 \pm 0.91$ & $2.90: 1$ & $1.22: 1$ \\
\hline $3 d$ & 652 & $55.2 \pm 2.6$ & $14.42 \pm 1.80$ & $5.63 \pm 0.61$ & $10.50 \pm 1.08$ & $2.91: 1$ & $1.26: 1$ \\
\hline
\end{tabular}

$N D$ not detectable. All data are represented as the mean $\pm S D, n=3$.

\section{Comparative $\mathrm{Cd}$ and Te tissue distributions}

Figure 3A illustrates the tissue distribution of $\mathrm{Cd}$ in ICR mice exposed to $\mathrm{CdTe} / \mathrm{ZnS}$ aqQDs. After intravenous injection, Cd mainly accumulated in the liver and kidneys. Accumulation was also observed in the spleen, lungs and heart. Cd was rarely distributed in the brain. The peak concentration and peak time of $\mathrm{Cd}$ in each organ after administration differed. They were: $22.1 \pm$ $4.74 \mathrm{ng} / \mathrm{g}$ at $24 \mathrm{~h}$ in the heart, $102.82 \pm 18.93 \mathrm{ng} / \mathrm{g}$ at $3 \mathrm{~d}$ in the liver, $42.04 \pm 11.22 \mathrm{ng} / \mathrm{g}$ at $7 \mathrm{~d}$ in the spleen, $18.03 \pm 1.27 \mathrm{ng} / \mathrm{g}$ at $24 \mathrm{~h}$ in the lungs and $66.75 \pm$ $12.75 \mathrm{ng} / \mathrm{g}$ at $7 \mathrm{~d}$ in the kidneys. By plotting the tissue concentrations versus time, we found that Cd elimination from the liver, kidneys and spleen was significantly slower than $\mathrm{Cd}$ elimination from the lungs and heart. Moreover, there were obvious increases in the $\mathrm{Cd}$ concentrations in the kidneys at $28 \mathrm{~d}$. At $28 \mathrm{~d}$ postexposure, 42.94, 14.69 and $42.60 \mathrm{ng} / \mathrm{g}$ remained in the liver, spleen and kidneys.

The distribution of Te in different tissues is shown in Figure 3B. The kidneys appeared to be the major target organs for Te deposition. Te was also deposited in the heart, liver, spleen and lungs. The brain contained only a very small amount of Te. The peak concentration and peak time of $\mathrm{Te}$ in each organ after administration

Table 2 Blood concentration-time curves of $\mathrm{Cd}$ and $\mathrm{Te}$ in mice exposed to CdTe/ZnS aqQDs

\begin{tabular}{cccc}
\hline Exposed time & Cd $(\mathbf{n g} / \mathbf{m l})$ & Te $(\mathbf{n g} / \mathbf{m l})$ & Cd:Te \\
\hline $1 \mathrm{~min}$ & $195.23 \pm 1.78$ & $73.60 \pm 2.40$ & $3.01: 1$ \\
$15 \mathrm{~min}$ & $142.40 \pm 3.40$ & $54.80 \pm 0.57$ & $2.95: 1$ \\
$30 \mathrm{~min}$ & $123.70 \pm 2.68$ & $47.60 \pm 3.32$ & $2.95: 1$ \\
$1 \mathrm{~h}$ & $108.80 \pm 1.98$ & $42.05 \pm 1.13$ & $2.94: 1$ \\
$6 \mathrm{~h}$ & $91.00 \pm 2.24$ & $41.70 \pm 3.11$ & $2.48: 1$ \\
$12 \mathrm{~h}$ & $66.23 \pm 1.90$ & $26.50 \pm 1.27$ & $2.30: 1$ \\
$24 \mathrm{~h}$ & $24.33 \pm 4.29$ & $10.10 \pm 4.25$ & $1.87: 1$ \\
$3 \mathrm{~d}$ & $\mathrm{ND}$ & $7.10 \pm 1.42$ & $\mathrm{ND}$ \\
\hline ND not detectable. All data are represented as the mean \pm SD, $\mathrm{n}=6$. &
\end{tabular}

differed. They were: $10.55 \pm 0.58 \mathrm{ng} / \mathrm{g}$ at $24 \mathrm{~h}$ in the heart, $9.63 \pm 0.56 \mathrm{ng} / \mathrm{g}$ at $3 \mathrm{~d}$ in the liver, $9.10 \pm 0.87 \mathrm{ng} / \mathrm{g}$ at $3 \mathrm{~d}$ in the spleen, $6.74 \pm 1.07 \mathrm{ng} / \mathrm{g}$ at $24 \mathrm{~h}$ in the lungs and $20.10 \pm 2.09 \mathrm{ng} / \mathrm{g}$ at $24 \mathrm{~h}$ in the kidneys. The peak times of Te in the heart, liver and lungs after administration were similar to $\mathrm{Cd}$ in these organs. In the spleen, Te concentrations increased during the first $3 \mathrm{~d}$ and reached peak concentrations $(9.10 \mathrm{ng} / \mathrm{g})$. However, from 3 to $28 \mathrm{~d}$, the Te concentrations did not vary significantly (9.10$8.13 \mathrm{ng} / \mathrm{g}$ ), indicating that elimination had rarely occurred. In the kidneys, the Te concentrations increased sharply during the first day (from 6.53 to $20.10 \mathrm{ng} / \mathrm{g}$ ), but elimination was significantly slower from $24 \mathrm{~h}(20.10 \mathrm{ng} / \mathrm{g})$ to 7 $\mathrm{d}(19.02 \mathrm{ng} / \mathrm{g})$. At $14 \mathrm{~d}$ post-exposure, the majority of Te had been eliminated, with only $2.89 \mathrm{ng} / \mathrm{g}$ remaining.

\section{Time-dependent changes in the $\mathrm{Cd}$ :Te ratios}

The Cd:Te ratios in the tissues were calculated over time and are shown in Table 4. At the $15 \mathrm{~min}$ time-point, they were: 2.77:1 (heart), 3.02:1 (liver), 3.02:1 (spleen), 2.94:1 (lungs), 3.21:1 (kidneys), and 3.22:1 (brain). All of the ratios were approximately $3: 1$, which corresponds to the molar ratio of $\mathrm{Cd}$ and $\mathrm{Te}$ in the $\mathrm{CdTe} / \mathrm{ZnS}$ aqQDs used in this study. Furthermore, different trends in the $\mathrm{Cd}: \mathrm{Te}$ ratios in the organs were observed. The Cd:Te

Table 3 Kinetic parameters of $\mathrm{Cd}$ and $\mathrm{Te}$ in mice exposed to CdTe/ZnS aqQDs

\begin{tabular}{cccc}
\hline Kinetic parameters & Unit & Cd & Te \\
\hline $\mathrm{Vd}$ & $\mathrm{ml} / \mathrm{kg}$ & $110.48 \pm 1.36$ & $115.91 \pm 2.44$ \\
$\mathrm{AUC}$ & $\mathrm{\mu g} \cdot \mathrm{h} / \mathrm{ml}$ & $2.16 \pm 0.07^{* *}$ & $0.99 \pm 0.13$ \\
$\mathrm{CL}$ & $\mathrm{ml} / \mathrm{h} / \mathrm{kg}$ & $10.40 \pm 0.48^{*}$ & $8.99 \pm 1.53$ \\
$t_{1 / 2 \alpha}$ & $\mathrm{h}$ & $0.14 \pm 0.06$ & $0.13 \pm 0.03$ \\
$t_{1 / 2 \beta}$ & $\mathrm{h}$ & $12.41 \pm 0.26^{*}$ & $14.40 \pm 1.33$ \\
\hline
\end{tabular}

$\mathrm{Vd}$, apparent volume of distribution, AUC, area under the blood concentrationtime profiles, $\mathrm{CL}$, clearance $t_{1 / 2 \alpha}$, distribution half-life, $t_{1 / 2 \beta}$, elimination half-life. Kinetic parameters ( $A \cup C, C L$ and $t_{1 / 2 \beta}$ ) of $C d$ were significantly different compared with those of Te in the blood, ${ }^{*} p<0.05,{ }^{* *} p<0.01$.

All data are represented as the mean $\pm S D, n=6$. 


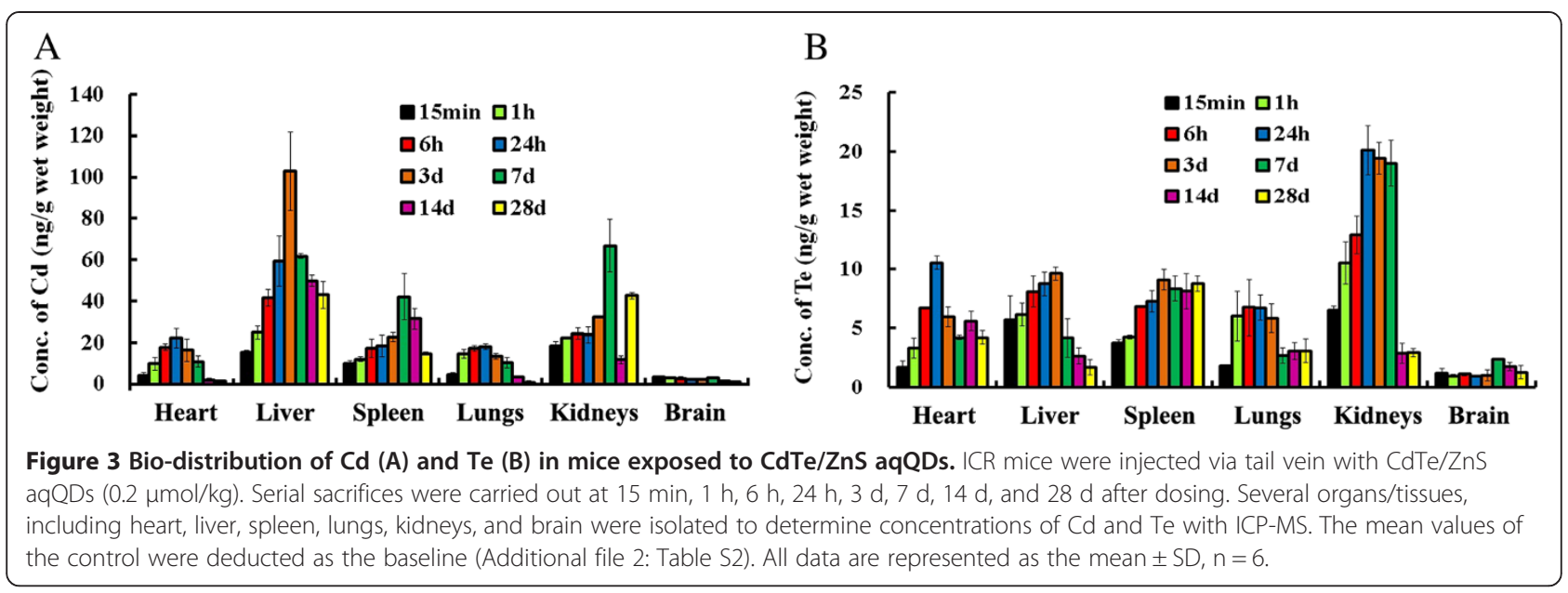

ratios in the heart did not differ significantly over a period of 7 days, but began to decrease gradually after $14 \mathrm{~d}$. In the liver, the $\mathrm{Cd}$ :Te ratios increased sharply with time from $1 \mathrm{~h}$ through $28 \mathrm{~d}$. In the spleen and lungs, the $\mathrm{Cd}$ :Te ratios did not change significantly over a period of $3 \mathrm{~d}$, increased at $7 \mathrm{~d}$ and decreased from $14 \mathrm{~d}$ on. In the kidneys, the Cd:Te ratios decreased at $24 \mathrm{~h}$ and increased gradually from $7 \mathrm{~d}$ on. These findings indicate that the CdTe/ZnS aqQDs steadily disintegrated in vivo. In addition, the degree of degradation of $\mathrm{CdTe} / \mathrm{ZnS}$ aqQDs differed in various organs.

\section{Discussion}

This study is an extension of our previous study, which was aimed at understanding the chemical fate of QDs in vivo. While there has been no lack of studies regarding the fate and biological safety of QDs, many of these studies were conducted in vitro [16-21]. Because cultured cells do not metabolize complex chemicals, in vitro cultures can not replicate complicated in vivo systems. Therefore, studies examining the actual chemical fate of QDs in intact biological systems (animal studies) are needed. This information is critical for the evaluation of the toxicity of QDs and other nanoparticles.

Table $4 \mathrm{Cd}: T e$ radios in the tissues of mice exposed to CdTe/ZnS aqQDs

\begin{tabular}{ccccccc}
\hline Exposed time & Heart & Liver & Spleen & Lungs & Kidneys & Brain \\
\hline 15 min & $2.77: 1$ & $3.02: 1$ & $3.02: 1$ & $2.94: 1$ & $3.21: 1$ & $3.22: 1$ \\
$1 \mathrm{~h}$ & $3.34: 1$ & $4.60: 1$ & $3.19: 1$ & $2.76: 1$ & $2.14: 1$ & $3.35: 1$ \\
$6 \mathrm{~h}$ & $3.03: 1$ & $5.86: 1$ & $2.88: 1$ & $2.91: 1$ & $2.41: 1$ & $2.81: 1$ \\
$24 \mathrm{~h}$ & $2.39: 1$ & $7.73: 1$ & $2.88: 1$ & $3.04: 1$ & $1.35: 1$ & $2.59: 1$ \\
$3 \mathrm{~d}$ & $3.14: 1$ & $12.12: 1$ & $2.82: 1$ & $2.59: 1$ & $1.87: 1$ & $2.35: 1$ \\
$7 \mathrm{~d}$ & $2.93: 1$ & $16.85: 1$ & $5.72: 1$ & $4.31: 1$ & $3.98: 1$ & $1.37: 1$ \\
$14 \mathrm{~d}$ & $0.41: 1$ & $21.42: 1$ & $4.38: 1$ & $1.18: 1$ & $4.66: 1$ & $0.87: 1$ \\
$28 \mathrm{~d}$ & $0.39: 1$ & $29.05: 1$ & $1.90: 1$ & $0.31: 1$ & $16.56: 1$ & $1.02: 1$ \\
\hline
\end{tabular}

QDs exhibit narrow emission profiles and can emit clear and bright colors based on their strong fluorescence intensities. A fluorescence spectrometer was used to reveal some of the parameters (size and concentration) of QDs. When QDs degrade (loss of surface atoms and decreases in the size of QDs), blue-shifts in the excitation fluorescence spectra and decreases in the quantum yield are observed [22]. However, using fluorescence intensity to quantify QDs in blood and tissues has been deemed to be problematic due to the high and variable background fluorescence that result from native blood and tissues. Moreover, the fluorescence of QDs is susceptible to environmental factors. For example, the PLQY has been demonstrated to change drastically as a result of surface chemistry, rearrangement of surface ligands, photoenhanced oxidization, and solvent effects. Any of these parameters can potentially cause large deviations in fluorescence measurements [13]. Therefore, using fluorescence intensity and peak wavelength in order to determine the chemical fate of QDs in vivo was deemed to be problematic. Inductively coupled plasmaatomic emission spectrometer (ICP-AES) and inductively coupled plasma-mass spectrometry (ICP-MS) are highly sensitive methods that can be used to detect most elements. For example, the detection limit for $\mathrm{Cd}$ can approach $0.1 \mathrm{ng} / \mathrm{ml}$ using ICP-MS. Fischer et al. [11] first tracked QDs via Cd measurements in the blood and organs of rats using ICP-AES and presented a quantitative report on the kinetic parameters and biodistribution of QDs in the rat. Several subsequent biological fate studies of QDs in vivo using ICP-AES and ICP-MS have been reported [12-14]. However, the ICP-AES or ICPMS analytical techniques were unable to distinguish whether Cd was bound within the QDs or had been released into the tissues. This distinction is important because bound $\mathrm{Cd}$ has no valence charge and, thus, is most likely much less biologically reactive or toxic than highly charged free $\mathrm{Cd}^{2+}$. 
In the work conducted by Fischer's group [11], QDs were incubated with whole blood, and samples were retrieved and centrifuged at various times in order to investigate whether the QDs interacted with blood components. The supernatant (plasma) was analyzed for QDs using fluorescence spectroscopy and ICP-AES, whereas the pellet was further analyzed using fluorescence microscopy. The authors verified using optical microscopy that the QDs exhibited minimal, nonspecific binding to the cellular blood components of the rat (e.g., erythrocytes). Other studies [13] mimicked the $\mathrm{pHs}$ of blood $(\mathrm{pH} 7.4)$ and the renal tubules $(\mathrm{pH} 4.8)$ in order to investigate the stability of $\mathrm{CdSeS} / \mathrm{SiO}_{2}$ QDs that had been stored in a buffer for five days. The results revealed that the maximal emission of $\mathrm{CdSeS} / \mathrm{SiO}_{2}$ QDs was not altered and that the fluorescence intensity was stable after five days of incubation in either $\mathrm{pH} 7.4$ or $\mathrm{pH} 4.8$ buffer solutions. Because the concentration of $\mathrm{Cd}$ in the supernatant of the experimental solution in both $\mathrm{pH}$ environments did not significantly differ from that in the phosphate buffered saline (PBS) blank, the authors concluded that $\mathrm{Cd}$ concentrations could be used to estimate the concentration of QDs in their in vivo studies. However, in vivo toxicity (or perceived toxicity) of the high surface area-to-volume ratio of QDs, which provides a large available surface for enzymatic degradation and the release of metallic ions, has been previously reported. Fitzpatrick et al. [23] studied the persistence of $\mathrm{CdSe} / \mathrm{ZnS}$ QDs that had been coated with MPEG 5000 (emitting at $655 \mathrm{~nm}$ ) in mice. They noted that immediately after injection into the tail vein, emissions related to the QDs were observed in the circulatory system and various organs, including the liver, spleen, lymph and bone marrow. The fluorescence signals observed were found to have been blue-shifted from the initial emission wavelengths, due to the loss of one monolayer of the nanoparticle. Within five days, the emission observed in the liver had faded, indicating that extreme degradation of the QDs had occurred with concomitant release of Cd. Pi et al. [24] labeled mouse embryonic stem cells (ESCs) with QDs and monitored QD-labeling using fluorescence microscopy for $72 \mathrm{~h}$. A rapid loss of QD-labeling in ESCs was observed within $48 \mathrm{~h}$. Transmission electron microscopy (TEM) analysis showed a dramatic decrease in QDs in the vesicles of ESCs at $24 \mathrm{~h}$ post-labeling, suggesting that the QDs may have degraded.

Here, we used fluorescence spectrometer and ICP-MS to investigate the chemical fate of $\mathrm{CdTe} / \mathrm{ZnS}$ aqQDs that had been stored in a buffer ( $\mathrm{pH}$ 7.4) for 3 days (Table 1). The experimental data indicated that the maximal emission was not altered. The concentrations of $\mathrm{Cd}, \mathrm{Te}$ and $\mathrm{Zn}$ ions released from the CdTe/ZnS QDs gradually increased over time, but were extremely low, and the ratios of $\mathrm{Cd}: \mathrm{Te}$ and $\mathrm{Zn}: \mathrm{Cd}$ did not vary significantly. This suggests that the size and composition of CdTe/ZnS
aqQDs stored in buffer did not differ significantly from those kept in situ [22,23]. On the other hand, the fluorescent intensity was reduced after a $6 \mathrm{~h}$ incubation in a $\mathrm{pH} 7.4$ buffer solution. This suggests that the nanocrystals of $\mathrm{CdTe} / \mathrm{ZnS}$ aqQDs formed surface defects in a pH 7.4 environment.

Next, the $\mathrm{Cd}$ and $\mathrm{Te}$ concentrations in the blood were measured using ICP-MS, the Cd:Te ratios were calculated, and $\mathrm{Cd}$ and Te blood kinetic analyses were conducted. As described in Tables 2 and 3, we observed differences in the $\mathrm{Cd}$ :Te ratios and $\mathrm{Cd}$ and $\mathrm{Te}$ blood kinetic parameters, suggesting that $\mathrm{CdTe} / \mathrm{ZnS}$ aqQDs break down in the blood. If $\mathrm{CdTe} / \mathrm{ZnS}$ aqQDs are chemically stable in the blood, steady or unchanged Cd:Te ratios in the blood over time would result. Furthermore, the blood kinetic parameters, CL and $t_{1 / 2 \beta}$ of $\mathrm{Cd}$ and $\mathrm{Te}$ would be similar. As shown in Tables 1 and 2, the relative fluorescent intensity of QDs in $\mathrm{pH}$ 7.4 buffer solution was reduced rapidly after $6 \mathrm{~h}$. The Cd:Te ratios also varied significantly after $6 \mathrm{~h}$ in the blood. These findings indicate that the stability of $\mathrm{CdTe} / \mathrm{ZnS}$ aqQDs in the blood of the mice is comparable to the stability in buffer solutions ( $\mathrm{pH}$ 7.4) [13]. QDs exhibited minimal, nonspecific binding to the cellular components of mice blood [11].

Lastly, we examined the uptake of $\mathrm{CdTe} / \mathrm{ZnS}$ aqQDs in various organs after leaving the bloodstream using ICP-MS. Contrary to their relatively transient fate in the blood, $\mathrm{Cd}$ and $\mathrm{Te}$ are preferentially distributed into organs and tissues (Figure $3 \mathrm{~A}$ and $\mathrm{B}$ ). When the specific tissue concentrations of $\mathrm{Cd}$ and $\mathrm{Te}$ were examined, $\mathrm{Cd}$ was observed to mainly accumulate in the liver and kidneys, which was in agreement with previous reports [13-15,25]. Unlike Cd, the kidneys appeared to be the major target organ for Te deposits. No significant changes in $\mathrm{Te}$ accumulation were observed in the heart, liver, spleen and lungs. On the other hand, we found that the $\mathrm{Cd}$ :Te ratios in various organs over time differed. Specially, at $1 \mathrm{~h}$ post-injection, significant changes in Cd:Te ratios were observed in the liver and kidneys. These findings further indicated that $\mathrm{CdTe} / \mathrm{ZnS}$ aqQDs degraded in specific organs, especially in the liver and kidneys [26], and implied that the chemical stability of $\mathrm{CdTe} / \mathrm{ZnS}$ aqQDs in vitro can not mimic the biological responses or consequences that occur in vivo. As shown in Table $1, \mathrm{CdTe} / \mathrm{ZnS}$ aqQDs are stable (the maximal emission and relative fluorescence intensity of $\mathrm{CdTe} /$ $\mathrm{ZnS}$ aqQDs were not altered) after a $1 \mathrm{~h}$ incubation in pH 7.4 buffer solutions.

Metallothionein (MT) is a protein that is inducible by various metallic elements, especially in the liver and kidneys. $\mathrm{Cd}$ is a potent inducer of MT, and Cd-MT is stable and stored. MT-bound $\mathrm{Cd}$ complexes are believed to be responsible for the long biological half-life of $\mathrm{Cd}$ in the body $[27,28]$. It was previously demonstrated that only 
free Cd release from QDs can induce MT [26]. In our study, over a period of $28 \mathrm{~d}$, we found that 42.94 and $42.60 \mathrm{ng} / \mathrm{g} \mathrm{Cd}$ remained in the liver and kidneys, suggesting that either significant disintegration of $\mathrm{CdTe} / \mathrm{ZnS}$ aqQDs had occurred, or that $\mathrm{Cd}$ had been released in the liver and kidneys and had transferred $\mathrm{Cd}$ as a Cd-MT complex during this time period. In the kidneys, a trend of increasing tissue concentrations was observed at $28 \mathrm{~d}$ (Figure 3A). The reabsorption of $\mathrm{Cd}$ indicates that renal elimination of $\mathrm{Cd}$ is more difficult [29]. The half-life of $\mathrm{Cd}$ in the kidneys appears to be very long. In the present study, very little $\mathrm{Cd}$ was distributed in the brain. The brain is a challenging organ for drug delivery because the blood brain barrier (BBB) functions as a gatekeeper guarding the body from exogenous substances. Small QDs may be transferred through a space of $20 \mathrm{~nm}$ that separates the capillary endothelium from the astrocytes, or QDs may interact with the receptors located at the BBB [30].

How the stable covalent bonds of QDs were broken biologically in the tissue remains unknown and requires further investigation. If the dissociation of $\mathrm{Cd}$ from QDs is closely associated with the toxicity of QDs in the tissues, knowing how to actually define the stability of QDs in vivo may inspire the development of new measures to inhibit or lessen such degradation, allowing QDs to remain in use medically, but in a much safer manner.

\section{Conclusions}

The chemical fate of QDs in vivo is of great importance. The degradation of QDs, and consequent release of free $\mathrm{Cd}$, can contribute to the overall toxicity of QDs. While QDs in biological systems have been traced using either fluorescent imaging methods or $\mathrm{Cd}$ tracking (ICP-MS) analyses, none of these analytical techniques or methods was actually able to define the chemical fate of QDs in vivo. By measuring blood kinetic parameters, the biodistributions of $\mathrm{Cd}$ and $\mathrm{Te}$ in $\mathrm{CdTe} / \mathrm{ZnS}$ aqQDs in mice, and the Cd:Te ratios in tissues, we clearly demonstrated that QDs are not as stable or biologically inert as they were once widely believed to be. In vitro, QDs are chemically stable and do not elicit the same biological responses or consequences as they do in vivo. Therefore, measuring $\mathrm{Cd}$ using ICP-AES or ICP-MS in order to quantify QDs in the plasma, organs, and excretion samples may not be accurate. New approaches to studying the fate of QDs in vivo should be considered. In summary, we believe that, although the present study was a relatively simple study, it provided very important information relative to the chemical fate and biological safety of QDs. We hope that our findings will inspire the manufacture of a new generation of QDs that are just as effective, but are also safer.

\section{Materials and methods}

\section{Characteristics of CdTe/ZnS aqQDs}

The $\mathrm{CdTe} / \mathrm{ZnS}$ aqQDs used in our experiments were prepared by Zhejiang University. The CdTe/ZnS aqQDs had a CdTe core and a ZnS shell. Thioglycolic acid (TGA) was used as a stabilizer. The molar ratio of $\mathrm{Cd}^{2+}: \mathrm{HTe}^{-}$: TGA was fixed at 3:1:3 (Cd:Te $=3: 1), \mathrm{Zn}^{2+}: \mathrm{Cd}^{2+}$ was fixed at $1: 1(\mathrm{Zn}: \mathrm{Cd}=1: 1)$. Glutathione $(\mathrm{GSH})$ was used as both a capping reagent and a sulfur source for the in situ growth of the $\mathrm{ZnS}$ shell on the CdTe core of the QDs. The $\mathrm{pH}$ value of the latter solution was fixed at 8.3. Prior to use in our experiments, the $\mathrm{CdTe} / \mathrm{ZnS}$ aqQDs stock solutions were centrifuged at $650 \times \mathrm{g}$ for $15 \mathrm{~min}$ at room temperature to remove large aggregates. The supernatants were then dialyzed for $4 \mathrm{~h}$ across a $10 \mathrm{kDa}$ cellulose membrane (Sigma) against a $0.1 \%$ solution of thioglycolate (sodium salt, Sigma) at $\mathrm{pH} 8.3$ to remove any free $\mathrm{Cd}$, $\mathrm{Te}, \mathrm{Zn}$ or other small molecules from the solutions [31-33]. The stock solutions were then further dialysed for $2 \mathrm{~h}$ against distilled water $(\mathrm{pH} 8.3)$ to remove unbound thioglycolate. The size distribution and surface characteristics of the CdTe/ZnS aqQDs were analyzed using AFM (Nano Scope 3D, Veeco, USA). Meanwhile, their fluorescence spectra, peak wavelengths and fluorescence intensity were measured using a fluorescence spectrometer (RF-5301, Shimadzu, Japan). The concentrations of $\mathrm{Cd}, \mathrm{Te}$ and $\mathrm{Zn}$ in the stock solution were determined as described below. Prior to injecting the mice, the $\mathrm{CdTe} /$ $\mathrm{ZnS}$ aqQDs solutions were freshly dissolved in a normal sodium medium containing PBS ( $\mathrm{pH}$ 7.4) and sonicated for $5 \mathrm{~min}$ in order to allow the CdTe/ZnS aqQDs particles to disperse evenly throughout the solution. The final concentrations of the solutions were adjusted to $50 \mathrm{nmol} / \mathrm{ml}$ (calculated based on the molar mass of Cd).

\section{Stability of CdTe/ZnS aqQDs in vitro}

The PLQYs of CdTe/ZnS aqQDs in situ (pH 8.3) were measured relative to Rhodamine 6G (Fluka) in ethanol over a period of 80 days. In addition, we mimicked the $\mathrm{pH}$ of blood ( $\mathrm{pH}$ 7.4) in order to investigate the stability of $\mathrm{CdTe} / \mathrm{ZnS}$ aqQDs in vitro. CdTe/ZnS aqQDs $(50 \mathrm{nmol} /$ $\mathrm{ml}$ ) were dissolved in PBS solutions ( $\mathrm{pH} 7.4)$ at $37^{\circ} \mathrm{C}$ and added to $10 \mathrm{kDa}$ dialysis tubes. The dialysis tubes were placed in polypropylene beakers containing PBS. The fluorescence spectra and relative fluorescent intensities of the solutions in the tubes were measured using a fluorescence spectrometer $15 \mathrm{~min}, 30 \mathrm{~min}, 1 \mathrm{~h}, 6 \mathrm{~h}, 24 \mathrm{~h}, 2 \mathrm{~d}$ and $3 \mathrm{~d}$ after the tubes were placed in the beakers. The concentrations of $\mathrm{Cd}, \mathrm{Te}$ and $\mathrm{Zn}$ in the filtrate were quantitatively measured using ICP-MS (7500ce, Agilent, USA). The lowest standard $(1 \mathrm{ng} / \mathrm{ml})$ on the calibration curve at which the analyte peak was identifiable and reproducible with a precision of less than $20 \%$ was designated as the lower limit of quantification. Calibration plots for $\mathrm{Cd}$, $\mathrm{Te}$ 
and $\mathrm{Zn}$ were obtained by injecting a series of standard solutions $\left(1,5,10,50\right.$, and $100 \mathrm{ng} / \mathrm{ml}$ in $2 \% \mathrm{HNO}_{3}$, flow rate: $1.0 \mathrm{ml} / \mathrm{min}$ ) into the ICP-MS. Both Cd:Te ratio and $\mathrm{Zn}: \mathrm{Cd}$ ratio were then calculated based on the concentrations of $\mathrm{Cd}, \mathrm{Te}$ and $\mathrm{Zn}$. The results for the PBS solutions were compared to those for the initial $\mathrm{CdTe} / \mathrm{ZnS}$ aqQDs.

\section{Animals}

Healthy male ICR mice (six weeks old) were purchased from Beijing (Military Medical Science Academy of the People's Liberation Army). The mice were housed in a ventilated, temperature-controlled, and standardized sterile animal room with a $12 \mathrm{~h}$ day/night cycle at the China Capital Medical University. The mice were allowed to acclimate to the animal room for 7 days prior to experimentation. All procedures used in this study were performed in accordance with animal welfare protocols that had been approved by the Capital Medical University Animal Care and Use Committee (approval number 2011-X-072).

\section{Animal treatment}

Mice weighing between 23.8 and 26.8 g were administered the $\mathrm{CdTe} / \mathrm{ZnS}$ aqQD solution via tail vein injection at a dose of $0.2 \mu \mathrm{mol} \mathrm{CdTe} / \mathrm{ZnS}$ aqQDs $/ \mathrm{kg}$ of body weight [13] (which was calculated based on the molar mass of $\mathrm{Cd}$ ). The mice in the control group were injected with an equivalent volume of normal saline. Preliminary observations of food intake, fur, behavior, mental status, urine and faeces were conducted daily for each mouse. At predetermined time points $(1 \mathrm{~min}, 15 \mathrm{~min}, 30 \mathrm{~min}, 1 \mathrm{~h}$, $6 \mathrm{~h}, 12 \mathrm{~h}, 24 \mathrm{~h}, 3 \mathrm{~d}, 7 \mathrm{~d}, 14 \mathrm{~d}$, and $28 \mathrm{~d}$ ), six mice from each exposed group were anesthetized using isoflurane. Retro-orbital blood was collected into Eppendorf tubes containing heparin $(10 \mu \mathrm{l}, 500 \mathrm{IU} / \mathrm{ml})$ and stored at $4^{\circ} \mathrm{C}$ for further analysis. The mice were then euthanized by cervical dislocation, and the hearts, livers, spleens, lungs, kidneys, and brains were collected. Meanwhile, the control mice were also killed, at predetermined time $(7 \mathrm{~d}, 14 \mathrm{~d}$, and $28 \mathrm{~d}$ ), strictly according to the procedure through which the exposed mice were treated. The body weight of each mouse and the weights of all organs were recorded. Tissues samples were stored at $-80^{\circ} \mathrm{C}$.

\section{Measurement of $\mathrm{Cd}$ and Te concentrations using ICP-MS}

Blood $(200 \mu \mathrm{l})$ and portions of the excised organs $(0.1-$ $0.5 \mathrm{~g}$ ), which had been rinsed with sterile saline to remove any remaining traces of blood, were soaked in nitric acid $\left(\mathrm{HNO}_{3}, 67 \%\right.$, MOS grade) in a glass beaker overnight. In addition, a $50 \mathrm{ng} / \mathrm{ml}$ indium $\left({ }^{115} \mathrm{In}\right)$ salt solution was added as an internal standard to ensure the accuracy and precision of the technique. To digest the samples, the beakers were heated to $110-120^{\circ} \mathrm{C}$ in a mixture of $\mathrm{HNO}_{3}$ and $\mathrm{H}_{2} \mathrm{O}_{2}$ (volume ratio 4:1) until the solution was colorless and clear. $\mathrm{H}_{2} \mathrm{O}_{2}$ was used to eliminate nitrogen oxide vapors. Lastly, the solution volume was fixed at $2 \mathrm{ml}$ using diluted nitric acid (2\%) and the solution was passed through a $0.45 \mu \mathrm{m}$ pore polyvinylidene fluoride membrane syringe filter. The concentrations of $\mathrm{Cd}$ and $\mathrm{Te}$ in the filtrates were quantitatively measured using ICP-MS. The mean values of $\mathrm{Cd}$ and $\mathrm{Te}$ in the control mice were deducted as the background for the blood and organs (heart, liver, spleen, lungs, kidneys, and brain) (Additional file 2: Table S2). Additionally, the Cd:Te ratios in administrative mice were calculated. The in vivo results were compared to that of initial CdTe/ZnS aqQDs.

\section{Kinetic analyses and statistical analyses}

Kinetic analyses of $\mathrm{Cd}$ and $\mathrm{Te}$ in the blood were carried out using Drug and Statistics (DAS) software version 2.0 (Mathematical Pharmacology Professional Committee of China, Shanghai, China). Kinetic parameters were calculated, including the apparent volume of distribution $(\mathrm{Vd}), \mathrm{AUC}, \mathrm{CL}$, as well as the distribution half-life $\left(t_{1 / 2 \alpha}\right)$ and $t_{1 / 2 \beta}$. The kinetic parameters were estimated separately for each animal. The data are expressed as the mean $\pm \mathrm{SD}$. $\mathrm{t}$-testing of the data was performed using the Statistical Package for Social Sciences version 13.0 (SPSS13.0). $\mathrm{p}$ values $<0.01$ or 0.05 were considered to be significant.

\section{Additional files}

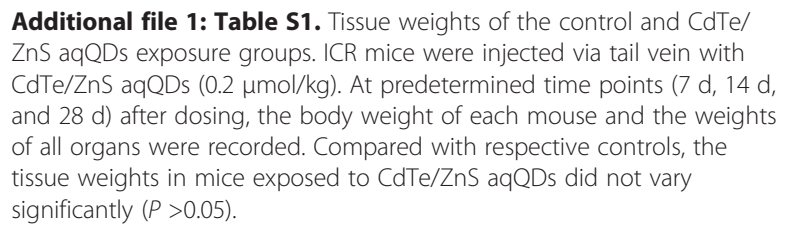

Additional file 1: Table S1. Tissue weights of the control and CdTe/ $\mathrm{ZnS}$ aqQDs exposure groups. ICR mice were injected via tail vein with CdTe/ZnS aqQDs $(0.2 \mu \mathrm{mol} / \mathrm{kg})$. At predetermined time points ( $7 \mathrm{~d}, 14 \mathrm{~d}$, and $28 \mathrm{~d}$ ) after dosing, the body weight of each mouse and the weights of all organs were recorded. Compared with respective controls, the tissue weights in mice exposed to CdTe/ZnS aqQDs did not vary significantly $(P>0.05)$.

Additional file 2: Table S2. Concentrations of $\mathrm{Cd}$ and Te of control mice. The detection limits for $\mathrm{Cd}$ and Te are $0.1 \mathrm{ppb}(\mathrm{ng} / \mathrm{ml})$.

\section{Abbreviations}

QDs: Quantum dots; PLQY: Photoluminescent quantum yield; Cd: Cadmium; Te: Tellurium; Zn: Zinc; AFM: Atomic force microscopy; ICP-MS: Inductively coupled plasma-mass spectrometry; ICP-AES: Inductively coupled plasmaatomic emission spectrometer; ESCs: Embryonic stem cells;

TEM: Transmission electron microscopy; MT: Metallothionein; BBB: Blood brain barrier; TGA: Thioglycolic acid; GSH: Glutathione; PBS: Phosphate buffered saline; In: Indium; Vd: Apparent volume of distribution; AUC: Area under the blood concentration-time profiles; $C L$ : Clearance; $t_{1 / 2 a}$ : Distribution half-life; $\mathrm{t}_{1 / 2 \beta}$ : Elimination half-life; DAS: Drug and statistics.

\section{Competing interests}

The authors declare that they have no competing financial interests.

\section{Authors' contributions}

NL supervised the animal experiments and participated in writing and editing the manuscript. YM and SHH synthesized the QDs. YC, HBS and QX are responsible for data and analysis. MMW, HW and YBL performed the experiments, as well as undertaking the ICP-MS analysis. ZWS and PLH are responsible for the study design and writing of the manuscript. All the authors read and approved the final manuscript. 


\section{Acknowledgements}

We gratefully acknowledge the financial support of the National Natural Science Foundation of China $(81273131 ; 81172704 ; 81230065)$. This work was also supported by the Funding Project for Academic Human Resources Development in Institutions of Higher Learning Under the Jurisdiction of Beijing Municipality, Science and Technology Programs of Suzhou (ZXG0920), and the Natural Science Foundation of Jiangsu province (BK2010242).

\section{Author details}

'Department of Toxicology and Sanitary Chemistry, School of Public Health Capital Medical University, No.10 Xitoutiao You An Men, Beijing 100069, China. ${ }^{2}$ Beijing Key Laboratory of Environmental Toxicology, Capital Medical University, No.10 Xitoutiao You An Men, Beijing 100069, China. ${ }^{3}$ Research Center for Analytical Instrumentation, Institute of Cyber-Systems and Control, State Key Lab. of Industrial Control Technology, Zhejiang University, 866 Yuhangtang Road, Hangzhou 310058, China. ${ }^{4}$ Basic Medical Experimental Teaching Center, Capital Medical University, No.10 Xitoutiao You An Men, Beijing 100069, China. ${ }^{5}$ College of Food and Bioengineering, Henan University of Science and Technology, Kaiyuan Ave 263, Luoyang 471023, China. ${ }^{6}$ Ministry of Education Key Laboratory of Environmental Medicine and Engineering, Southeast University, No.87 Dingjiaqiao, Nanjing 210009, China.

Received: 24 February 2013 Accepted: 2 August 2013

Published: 6 August 2013

\section{References}

1. Michalet X, Pinaud FF, Bentolila LA, Tsay JM, Doose S, Li JJ, Sundaresan G, Wu AM, Gambhir SS, Weiss S: Quantum dots for live cells, in vivo imaging, and diagnostics. Science 2005, 307:538-544.

2. Smith AM, Duan H, Mohs AM, Nie S: Bioconjugated quantum dots for in vivo molecular and cellular imaging. Adv Drug Deliv Rev 2008, 60:1226-1240.

3. So MK, Xu CJ, Loening AM, Gambhir SS, Rao JH: Self-illuminating quantum dot conjugates for in vivo imaging. Nat Biotechnol 2006, 24:339-343.

4. Hossain Z, Huq F: Studies on the interaction between $\mathrm{Cd}(2+)$ ions and DNA. J Inorg Biochem 2002, 90:85-96.

5. Bertin G, Averbeck D: Cadmium: cellular effects, modifications of biomolecules, modulation of DNA repair and genotoxic consequences (a review). Biochimie 2006, 88:1549-1559.

6. Ambrosone A, Mattera L, Marchesano V, Quarta A, Susha AS, Tino A, Rogach AL, Tortiglione C: Mechanisms underlying toxicity induced by CdTe quantum dots determined in an invertebrate model organism. Biomaterials 2012, 33:1991-2000.

7. He Y, Sai LM, Lu HT, Hu M, Lai WY, Fan QL, Wang LH, Huang W: Microwaveassisted synthesis of water-dispersed CdTe nanocrystals with highly luminescent efficiency and narrow size distribution. Chem Mater 2007, 19:359-365.

8. Hu M, Yan J, He Y, Lu HT, Weng LX, Song SP, Fan CH, Wang LH: Ultrasensitive, multiplexed detection of cancer biomarkers directly in serum by using a quantum dot-based microfluidic protein chip. ACS Nano 2010, 4:488-494.

9. He Y, Lu HT, Su YY, Sai LM, Hu M, Fan CH, Wang LH: Ultra-photostable, non-cytotoxic, and highly fluorescent quantum nanospheres for longterm, highspecificity cell imaging. Biomaterials 2011, 32:2133-2140

10. Taylor A: Biochemistry of tellurium. Biol Trace Elem Res 1996, 55:231-239.

11. Fischer HC, Liu L, Pang KS, Chan WCW: Pharmacokinetics of nanoscale quantum dots: in vivo distribution, sequestration, and clearance in the rat. Adv Funct Mater 2006, 16:1299-1305.

12. Yang RSH, Chang LW, Wu JP, Tsai MH, Wang HJ, Kuo YC, Yeh TK, Yang CS, Lin P: Persistent tissue kinetics and redistribution of nanoparticles, quantum dot 705, in mice: ICP-MS quantitative assessment. Environ Health Perspect 2007, 115:1339-1343.

13. Chen Z, Chen H, Meng H, Xing GM, Gao XY, Sun BY, Shi XL, Yuan H, Zhang CC, Liu R, Zhao F, Zhao YL, Fang XH: Bio-distribution and metabolic paths of silica coated CdSeS quantum dots. Toxicol Appl Pharmacol 2008 230:364-371.

14. Su YY, Peng F, Jiang ZY, Zhong YL, Lu YM, Jiang XX, Huang Q, Fan CH, Lee ST, He Y: In vivo distribution, pharmacokinetics, and toxicity of aqueous synthesized cadmium-containing quantum dots. Biomaterials 2011, 32:5855-5862.

15. Han Y, Xie GY, Sun ZW, Mu Y, Han SH, Xiao Y, Liu N, Wang H, Guo CX, Shi ZX, $L i Y B$, Huang PL: Plasma kinetics and biodistribution of water-soluble CdTe quantum dots in mice: a comparison between $\mathrm{Cd}$ and Te. J Nanopart Res 2011, 10:5373-5380.
16. Kirchner C, Liedl T, Kudera S, Pellegrino T, Munoz Javier A, Gaub HE, Stolzle S, Fertig N, Parak WJ: Cytotoxicity of colloidal CdSe and CdSe/ZnS nanoparticles. Nano Lett 2005, 5:331-338.

17. Su YY, He Y, Lu HT, Sai LM, Li QN, Li WX, Wang LH, Shen PP, Huang Q, Fan CH: The cytotoxicity of cadmium based, aqueous phase-synthesized, quantum dots and its modulation by surface coating. Biomaterials 2009, 30:19-25.

18. Su YY, Hu M, Fan CH, He Y, Li QN, Li WX, Wang LH, Shen PP, Huang Q. The cytotoxicity of $\mathrm{CdTe}$ quantum dots and the relative contributions from released cadmium ions and nanoparticle properties. Biomaterials 2010, 31:4829-4834.

19. Xu M, Deng GF, Liu SS, Chen S, Cui D, Yang LM, Wang QQ: Free cadmium ions released from CdTe-based nanoparticles and their cytotoxicity on Phaeodactylum tricornutum. Metallomics 2010, 2:469-473.

20. Zheng H, Chen GC, Song FM, DeLouise LA, Lou ZY: The cytotoxicity of OPA-modified CdSe/ZnS core/shell quantum dots and its modulation by silibinin in human skin cells. J Biomed Nanotechnol 2011, 7:648-658.

21. Yan $M$, Zhang $Y, X u K$, Fu T, Qin H, Zheng X: An in vitro study of vascular endothelial toxicity of CdTe quantum dots. Toxicology 2011, 282:94-103.

22. Derfus AM, Chan WCW, Bhatia SN: Probing the cytotoxicity of semiconductor quantum dots. Nano Lett 2004, 4:11-18.

23. Fitzpatrick JAJ, Andreko SK, Ernst LA, Waggoner AS, Ballou B, Bruchez MP: Long-term persistence and spectral blue shifting of quantum dots in vivo. Nano Lett 2009, 9:2736-2741.

24. Pi QM, Zhang WJ, Zhou GD, Liu W, Cao YL: Degradation or excretion of quantum dots in mouse embryonic stem cells. BMC Biotechnol 2010, 10:36-44.

25. Kennel SJ, Woodward JD, Rondinone AJ, Wall J, Huang Y, Mirzadeh S: The fate of MAb-targeted $\mathrm{Cd}(125 \mathrm{~m}) \mathrm{Te} / \mathrm{ZnS}$ nanoparticles in vivo. NuCl Med Biol 2008, 35:501-514

26. Lin $\mathrm{CH}$, Chang LW, Chang H, Yang MH, Yang CS, Lai WH, Chang WH, Lin PP: The chemical fate of the $\mathrm{Cd} / \mathrm{Se} / \mathrm{Te}$-based quantum dot 705 in the biological system: toxicity implications. Nanotechnology 2009, 20:1-9.

27. Liu J, Liu Y, Michalska AE, Choo KH, Klaassen CD: Distribution and retention of cadmium in metallothionein I and II null mice. Toxicol Appl Pharmacol 1996, 136:260-268.

28. Klaassen CD, Liu J, Choudhuri S: Metallothionein: an intracellular protein to protect against cadmium toxicity. Annu Rev Pharmacol Toxicol 1999, 39:267-294.

29. Satarug S, Baker JR, Reilly PEB, Moore MR, Williams DJ: Cadmium levels in the lung, liver, kidney cortex and urine samples from Australians without occupational exposure to metals. Arch Environ Health 2002, 57:69-77.

30. Singh S, Nalwa HS: Nanotechnology and health safety-toxicity and risk assessments of nanostructured materials on human health. J Nanosci Nanotechnol 2007, 7:3048-3070

31. Gagne F, Auclair J, Turcotte P, Fournier M, Gagnon C, Sauve S, Blaise C: Ecotoxicity of $\mathrm{CdTe}$ quantum dots to freshwater mussels: impacts on immune system, oxidative stress and genotoxicity. Aquat Toxicol 2008, 86:333-340.

32. Peyrot C, Gagnon C, Gagne F, Willkinson KJ, Turcotte P, Sauve S: Effects of cadmium telluride quantum dots on cadmium bioaccumulation and metallothionein production to the freshwater mussel, Elliptio complanata. Comp Biochem Phys C 2009, 150:246-251.

33. Li H, Shih WY, Shih WH: Highly photoluminescent and stable aqueous ZnS quantum dots. Ind Eng Chem Res 2010, 49:579-582.

doi:10.1186/1743-8977-10-37

Cite this article as: Liu et al:: Degradation of aqueous synthesized CdTe/ $\mathrm{ZnS}$ quantum dots in mice: differential blood kinetics and biodistribution of cadmium and tellurium. Particle and Fibre Toxicology 2013 10:37. 